Tohoku J. Exp. Med., 2006, 208, 1-8

Invited Review

\title{
Genetically Modified Dendritic Cells for Therapeutic Immunity
}

\author{
TOSHIAKI KIKUCHI \\ Department of Respiratory Oncology and Molecular Medicine, Institute of \\ Development, Aging and Cancer, Tohoku University, Sendai, Japan
}

\begin{abstract}
KIKUCHI, T. Genetically Modified Dendritic Cells for Therapeutic Immunity. Tohoku J. Exp. Med., 2006, 208 (1), 1-8 — Dendritic cells are professional antigen presenting cells, which show an extraordinary capacity to initiate primary immune responses by stimulating T cells. This established function of dendritic cells has attracted much attention in efforts to develop useful vaccines for the treatment of cancer and infectious diseases. Designing effective strategies to generate clinical dendritic cell-based vaccine protocols remains a challenging field of research. The successful realization of immunotherapy utilizing dendritic cells will depend on modifications of these protocols to optimize the natural stimulatory properties of dendritic cells, such as genetic modification of dendritic cells. This review focuses on dendritic cell gene modifications for enhancing the multiple effector functions of dendritic cells, including viral and non-viral gene transfer into dendritic cells, and a variety of transferred genes, such as those encoding antigens, co-stimulatory molecules, cytokines, and chemokines. - dendritic cell; cellular vaccine; genetic modification; cancer; infectious diseases
\end{abstract}

(C) 2006 Tohoku University Medical Press

Dendritic cells (DCs) are professional antigen presenting cells, which possess an exquisite capacity to generate primary immune responses (Banchereau et al. 2000; Mellman and Steinman 2001). DCs are strategically situated at the interface of potential pathogen entry sites to capture antigens (Fig. 1). After the antigen uptake, they process these antigens into small peptides and move into secondary lymphoid organs to present the antigenic peptides and activate lymphocytes. For the activation, DCs undergo maturation and become fully activated DCs, which express high levels of cell-surface major histocompatibility complex (MHC) antigen complexes and costimulatory molecules. The responding lymphocytes include naive $\mathrm{T}$ cells, helper $\mathrm{CD}^{+} \mathrm{T}$ cells, cytolytic $\mathrm{CD}^{+} \mathrm{T}$ cells, naïve $\mathrm{B}$ cells, memory $\mathrm{B}$ cells, natural killer (NK) cells and natural killer T (NKT) cells, all of which are critical elements of immunization. Therefore, because of the immunostimulatory function of DCs, they are fundamental targets for vaccination in cancer and infectious diseases, and ex vivo-generated, antigen-loaded DCs have been used as vaccines to augment the host's immune defense (Nestle et al. 2001; Cerundolo et al. 2004; Figdor et al. 2004;

Received October 18, 2005; revision accepted for publication October 24, 2005.

Correspondence: Toshiaki Kikuchi, M.D., Ph.D., Department of Respiratory Oncology and Molecular Medicine, Institute of Development, Aging and Cancer, Tohoku University, 4-1 Seiryomachi, Aoba-ku, Sendai 980-8575, Japan.

e-mail: kikuchi@idac.tohoku.ac.jp

Dr. T. Kikuchi is a recipient of the 2004 Gold Prize, Tohoku University School of Medicine. 


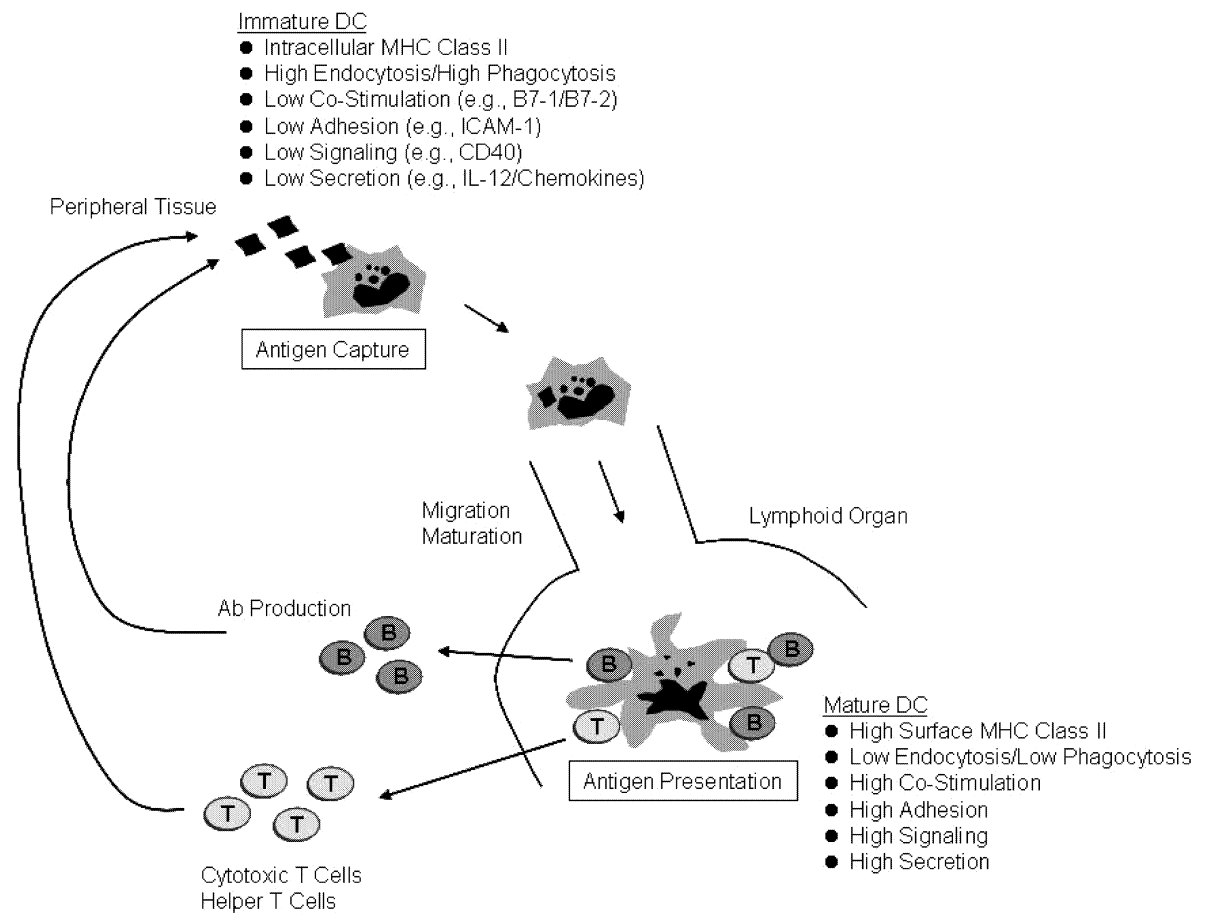

Fig. 1. The immunobiology of DCs. After antigen capture in peripheral tissues, immature DCs migrate to lymphoid organs where, after maturation, they display MHC-peptide complexes, which allow activation, expansion and differentiation of antigen-specific lymphocytes. The activated lymphocytes eventually function as effector cells in adaptive immunity against the initial antigens. The main properties of immature and mature DC are shown.

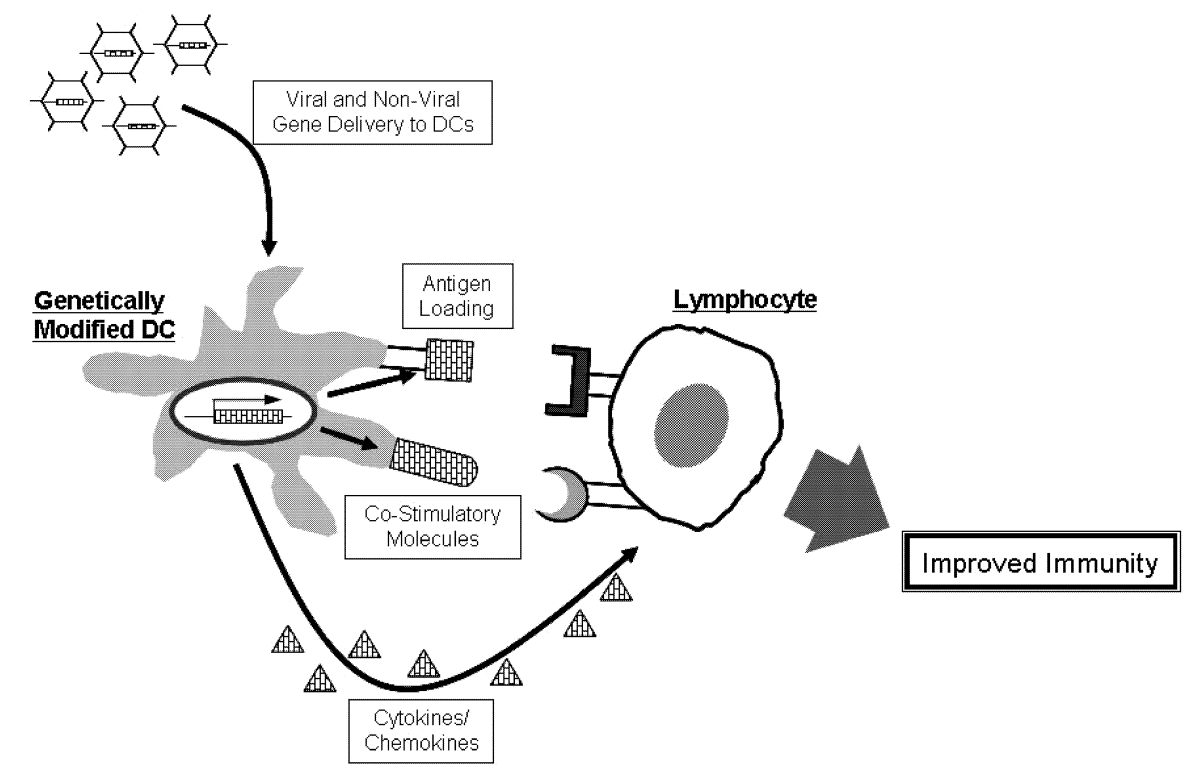

Fig. 2. The gene modification strategies of DCs. To exploit the full potential of DCs, several strategies of the DC gene modification have been developed by using viral and non-viral gene transfer into DCs, and a variety of transferred genes, such as those encoding antigens, co-stimulatory molecules, cytokines, and chemokines. 
Banchereau and Palucka 2005). The safety and immunogenicity of DC immunotherapy in the treatment of patients with cancer or chronic HIV infection have been demonstrated, thereby providing an impetus for further investigation of this approach (Davis et al. 2003; Lu et al. 2004). To date, more than $98 \mathrm{DC}$ vaccine studies involving over 1,000 cancer patients have been conducted, and more than 60 clinical studies of DC vaccines for cancer patients are underway. However, the introduction of DC immunotherapy in meaningful phase 3 clinical studies is hampered by inadequate evidence of objective clinical efficacy, e.g., tumor regression evaluated by a set of standard oncological criteria. Thus, this low clinical effectiveness raises the important question of how the DC vaccine strategy can be optimized so as to exploit the full potential of these immunostimulatory cells (Steinman and Pope 2002). To address this issue, we discuss recent progress in our knowledge of immunotherapy using gene-modified DCs (Fig. 2).

\section{Gene delivery systems for DC}

In an attempt to design more effective DC vaccines, investigators have modified enriched populations of DCs in vitro with viral and non-

TABLE 1. Advantages and disadvantages of the viral vector systems (Breckpot et al. 2004)

\begin{tabular}{|c|c|c|}
\hline Vector system & Advantages & Disadvantages \\
\hline Adenovirus vectors & $\begin{array}{l}\text { High titers } \\
\text { Large insertional capacity } \\
\text { High transgene expression } \\
\text { High transduction efficiencies }\end{array}$ & $\begin{array}{l}\text { Transient expression of the transgene } \\
\text { Vector immunogenicity }\end{array}$ \\
\hline Adeno-associated virus vectors & $\begin{array}{l}\text { Stable/high transgene expression } \\
\text { Infects dividing and non-dividing cells }\end{array}$ & $\begin{array}{l}\text { Limited insertional capacity } \\
\text { Production difficulties } \\
\text { Possible insertional mutagenesis } \\
\text { Varying transduction efficiencies }\end{array}$ \\
\hline Herpes virus vectors & $\begin{array}{l}\text { Multi-copy vector } \\
\text { Large insertional capacity } \\
\text { High transduction efficiencies }\end{array}$ & $\begin{array}{l}\text { Transient expression } \\
\text { Induces DC maturation }\end{array}$ \\
\hline Vaccinia virus vectors & $\begin{array}{l}\text { Infects dividing and non-dividing cells } \\
\text { Large insertional capacity } \\
\text { Moderate transduction efficiency }\end{array}$ & $\begin{array}{l}\text { Transient expression of the transgene } \\
\text { Induces DC maturation }\end{array}$ \\
\hline Retrovirus-based vectors & Stable transgene expression & $\begin{array}{l}\text { Low titers } \\
\text { Limited insertional capacity } \\
\text { Infects only dividing cells } \\
\text { Possible insertional mutagenesis }\end{array}$ \\
\hline Lentivirus-based vectors & $\begin{array}{l}\text { High titers } \\
\text { Stable transgene expression } \\
\text { High transduction efficiencies } \\
\text { Infects dividing and non-dividing cells } \\
\text { Improved safety }\end{array}$ & $\begin{array}{l}\text { Limited insertional capacity } \\
\text { Possible insertional mutagenesis }\end{array}$ \\
\hline
\end{tabular}


viral gene delivery systems (Breckpot et al. 2004). The viral systems utilize various vectors derived from adenovirus, adeno-associated virus, herpes virus, vaccinia virus, retrovirus, lentivirus. The viral gene transfer methods generally reach high efficiencies of gene transfer, although there are some safety concerns associated with their clinical use. The advantages and disadvantages of each of these viral vector systems are summarized in Table 1. In our laboratory, the replicationdeficient adenoviral vector system has been adopted for gene transduction into DCs, because the high transgene expression following the extremely high transduction efficiency (i.e., almost $100 \%$ ) would be suitable for the induction of a robust immune response, and transient transgene expression lasting about 1 week would not likely make a major hurdle for an initiation of immunity (Arthur et al. 1997; Dietz and VukPavlovic 1998; Frey et al. 1998; Mulders et al. 1998). Although the immunogenicity of the adenoviral particles and the residual adenoviral gene products in the vector backbone are assumed to be a major drawback of the adenovirus-based system, concerns about the generation of antiadenoviral immunity were not supported by data obtained from in vivo mouse studies (Brossart et al. 1997; Kaplan et al. 1999). Moreover, that no major side effects have been reported in cancer patients administered with DCs transduced with adenovirus encoding p53, PSA, MART-1 or gp100 suggests the clinical potential of adenoviral modified DCs as tools for immunotherapy (Rosenberg et al. 1998; Mincheff et al. 2000; Buller et al. 2002; Habib et al. 2002).

Non-viral gene delivery systems for DCs employ chemical and physical transfection methods, which are relatively simple and easy (Lundqvist and Pisa 2002). In contrast with the viral gene delivery system, the greatest advantage of the non-viral system is that the risk associated with the insertion of foreign nucleic acids such as viral DNA is eliminated. Data provided by early basic studies indicate that the physical transfection methods (e.g., electroporation and gene gun) are generally more efficient for the nucleic acid transfection of DCs than the chemical transfection methods (e.g., calcium phosphate precipitation, DEAE-dextran and lipofection), despite the fact that the physical methods are potentially toxic for DCs (Rouse et al. 1994; Arthur et al. 1997; Van Tendeloo et al. 1998).

\section{Antigen loading}

Numerous studies have investigated the loading of MHC class I and class II molecules at the cell surface of exogenous DCs with peptides derived from defined antigens in an effort to induce endogenous T cell responses (Gilboa 1999; Wang et al. 1999). Some clinical trials of cancer vaccines based on tumor antigen-pulsed DCs have supported their safety and efficacy (Cerundolo et al. 2004). However, this approach has several limitations: (1) the limited number of wellcharacterized antigens, (2) the requirement for matching defined peptides with MHC haplotypes, (3) the stimulation of a restricted repertoire of $\mathrm{T}$ cell clones, and finally (4) the relatively brief presentation of exogenous peptide-MHC complexes, leading to insufficient antigen presentation of the injected DCs (Banchereau and Palucka 2005). In contrast with pulsing DCs with peptide epitopes, modification of DCs with genes encoding antigens has been shown in various mouse models to provide prolonged presentation of multiple epitopes by various class I and class II MHC haplotypes with the induction of long-term T-cell immunity against the corresponding antigens (Murphy et al. 2005). Nevertheless, from the data of these preclinical studies, the clinical application of this approach was anticipated to be limited (Ribas et al. 2002).

As an alternative to DNA-encoded antigens, several studies utilized mRNA synthesized in vitro from cDNA or isolated from tissues or cells for the DC-based vaccination and demonstrated that antigen-specific $\mathrm{T}$ cell responses could be generated (Gilboa and Vieweg 2004). In particular, transfection of DCs with mRNA encoding defined and well characterized antigens appears promising, since mRNA whose sequence is known can be easily generated in vitro as a noncell-derived product that is ready for the clinical use. Although there were concerns that RNA was 
extremely labile and could not endure the conventional transfection protocols, the immunostimulatory capacity of mRNA-transfected DCs has now been experimentally validated in many laboratories and extended to several clinical trials as cancer vaccines. Some of these trials yielded encouraging results with evidence of tumor-specific $\mathrm{T}$ cell expansion and no toxicity in immunized patients, demonstrating the clinical feasibility of this therapeutic approach (Heiser et al. 2002; $\mathrm{Su}$ et al. 2003).

\section{Co-stimulatory molecules}

In an attempt to enhance the immunostimulatory efficacy of the genetic vaccines, we have sought to modify DCs to express costimulatory molecules such as CD40 ligand (CD40L), the ligand for CD40 on antigen presenting cells (Kikuchi and Crystal 1999; Kikuchi et al. 2000a, 2000b, 2001). Based on the knowledge that the triggering of CD40 on DCs substitutes for the requirement of $\mathrm{CD}^{+} \mathrm{T}$ cells in activating DCs, we have genetically modified DCs with a recombinant adenovirus to express CD40L, and hypothesized that the modified DCs would be able to activate themselves and thus initiate an antigenspecific immune response without $\mathrm{CD} 4^{+} \mathrm{T}$ cell help (O'Sullivan and Thomas 2003). Two major different pieces of evidence in our preclinical animal studies substantiated that this hypothesis is valid. In a tumor-bearing mouse model, intratumoral injection of CD40L-modified DCs elicited tumor-specific cytotoxic T-lymphocyte (CTL) immune responses that suppressed the growth of established tumors in wild-type and CD4-/- mice and enhanced the survival; in a mouse model of chronic pulmonary infection with Pseudomonas aeruginosa, CD40L-modified DCs pulsed with heat-killed $P$. aeruginosa initiated Pseudomonasspecific humoral immune responses in vivo in wild-type and CD4-/- mice, and protected immunized wild-type and CD4-/-, but not B-cell-/mice, from lethal intrapulmonary challenge with P. aeruginosa.

The coexpression of RANK (receptor activator of $\mathrm{NF}-\kappa \mathrm{B}$ ) and its $\mathrm{T}$ cell-expressed ligand RANKL on DCs has been found to induce signifi- cantly elevated numbers of antigen-specific, IFN- $\gamma$-secreting effector and memory T cells in immunized mice (Wiethe et al. 2003). The augmentation of effector $T$ cell responses was relevant to the up-regulation of CD80 and CD86 expression on DCs transduced with RANK/ RANKL, suggesting a mechanism for enhanced $\mathrm{T}$ cell activation/survival.

\section{Cytokines}

There is growing evidence that the cytokine production by DCs is an important factor that determines the progressive differentiation of $\mathrm{CD}^{+}{ }^{+} \mathrm{T}$ cells that receive $\mathrm{T}$ cell receptor (TCR) triggering by peptide-MHC complexes on DCs, which is particularly relevant in the case of interleukin (IL)-12, the prototypic Th1-polarizing cytokine (Trinchieri 1993). Since Th1 and CTL immune responses are necessary for effective anti-tumor immunity, genetic modification of DCs with IL-12 has been investigated in a mouse tumor model (Nishioka et al. 1999). Using DCs retroviral-transduced with genes encoding mouse IL-12 to stably express bioactive IL-12 protein at high levels, the authors observed the regression of weakly immunogenic tumors after intratumoral injection. Investigators also confirmed that intratumoral injection with IL-12-transduced DCs induced specific Th1- polarizing responses to the tumor in regional lymph nodes and spleen at levels greater than those of IL-12-transduced fibroblasts or non-transduced DCs. Based on the above results utilizing IL-12-engineered DCs in vitro and in mouse studies, cancer treatment with IL12-gene-modified DCs has proceeded to the clinical trial stage (Murphy et al. 2005).

IL-18 is another Th1-polarizing cytokine with important immunoregulatory functions, including the ability to induce high levels of IFN$\gamma$ secretion from NK and T cells, and DCs infected with a recombinant adenovirus encoding IL18(AdIL18) to secrete IL-18 have been demonstrated to have potent T-cell stimulatory capacity, as measured by the increased surface expression of MHC and costimulatory molecules and an induced, mixed leukocyte reaction in vitro (Okamura et al. 1995; Tatsumi et al. 2002). The 
immunostimulatory property of DCs expressing IL-18 has further been tested in a mouse sarcoma model, with the result that immunization of $\mathrm{BALB} / \mathrm{c}$ mice bearing sarcoma tumors established 7 days before with tumor peptide-pulsed AdIL18infected DCs significantly inhibited the growth of the tumors and lead to complete regression of some of the established tumors. Moreover, the synergistic effect of IL-12 and IL-18 to drive Th1type immune responses was reported in DCs engineered to secrete both of the Th1-polarizing cytokines (Tatsumi et al. 2003).

Other cytokine genes such as TNF- $\alpha$ and IL-7 have also been used with the aim of facilitating the capacity of DCs to stimulate T cells (Chen et al. 2002; Sharma et al. 2003). Chen et al. (2002) showed that DCs genetically modified to express TNF- $\alpha$ in combination with HER-2/neu antigen showed the up-regulation of immunologically important CD40, CD86, and ICAM-1, and stimulated significant anti-HER-2/neu immunity in vivo, which protected $8 / 8$ mice from challenge with MCA26/HER-2 tumor cells. In another mouse study, it was observed that injection of DCs transduced with an adenovirus vector expressing IL-7 in the axillary lymph node region led to a marked reduction in tumor burden accompanied by extensive lymphocytic infiltration of the tumors as well as an increase in IFN- $\gamma, \mathrm{IL}-12$, and anti-angiogenic chemokines, such as IP-10/ CXCL10 and MIG/CXCL9.

\section{Chemokines}

Since a crucial requirement in the generation of an effective immune response is the DC attraction of $\mathrm{T}$ cells for antigen presentation, DCs modified to secrete $\mathrm{T}$ cell-attracting chemokines may also find a use in immunotherapy against cancer and infectious diseases (Homey et al. 2002).

As anti-cancer cellular vaccines, early studies in mice showed that lymphotactin/XCL1 genemodified DCs were capable of attracting both $\mathrm{CD}^{+}$and $\mathrm{CD}^{+} \mathrm{T}$ cells in an in vitro chemotaxis assay, and immunization with Mut1 peptidepulsed lymphotactin/XCL1 gene-modified DCs succeeded in protecting mice from Mut $1^{+} 3 \mathrm{LL}$ tumor cell challenge with the induction of specific
CTL against Mut1 $^{+}$3LL tumor cells (Cao et al. 1998). SLC/CCL21 gene-modified DCs have also been demonstrated to induce the recruitment of $\mathrm{T}$ cells in vivo, and, as a treatment for established mouse tumors, provided better inhibition of tumor growth than control DCs (Kirk et al. 2001). This finding was supported by later mouse studies showing that intratumoral injection of DCs expressing SLC/CCL21 enhanced the T cell recruitment and the anti-tumor response when compared to the treatment with fibroblasts expressing SLC/CCL21 (Yang et al. 2004). Recently, among DCs expressing three chemokines including lymphotactin/XCL1, SLC/CCL21 and Mig/CXCL9, SLC/CCL21 gene-modified DCs were proved to act as the most potent adjuvant for antigen delivery to induce protective antitumor immunity through the preferential attraction of T cells (Matsuyoshi et al. 2004).

Against the infectious agents Pseudomonas aeruginosa and Legionella pneumophila we have explored immunization strategies by using DCs genetically modified with chemokine genes, including MDC/CCL22 and fractalkine/CX3CL1, respectively (Kikuchi and Crystal 2001; Kikuchi et al. 2005). In this regard, we hypothesized that genetic modification of DCs ex vivo with a recombinant adenovirus vector to overexpress MDC would enhance the ability of DCs to induce a Th2-dominant humoral immune response for the attraction of Th2 phenotype T lymphocytes, and evaluated and confirmed the concept by challenging mice with lethal $P$. aeruginosa infection after immunization with MDC/CCL22-modified DCs pulsed with heat-killed $P$. aeruginosa. As a result, using the genetically MDC/CCL22-engineered DCs was demonstrated to be a potentially effective approach for vaccination against extracellular microbes like $P$. aeruginosa. We also found that ex vivo gene modification with the gene encoding fractalkine/CX3CL1 could be employed to support the development of Th1 cell-mediated immunity to intracellular bacteria such as $L$. pneumophila.

\section{Concluding Remarks}

To address the question of whether the origi- 
nal promise of DC-based immunization could be translated into more effective therapies, we refer to a recently published evaluation of clinical outcomes in several vaccination trials that tested peptides, antigens expressed by recombinant viruses, and antigen-presented DCs (Cerundolo et al. 2004). In the assessment, the DC-based strategies elicited responses on the same order of magnitude as those induced by other immunization protocols, and a higher percentage of responding patients was observed using some DC vaccinations. Although there may be advantages to DCbased immunotherapy in a clinical setting, the protocols must be further optimized to enhance the adjuvant properties of DCs. We believe that the potential of the gene modification strategies described above can be further improved to yield even more potent immunostimulatory cells.

\section{Acknowledgments}

The author is grateful to Drs. T. Nukiwa and R.G. Crystal for helpful guidance, to many colleagues in our laboratory for kind assistance, and to B. Bell for reading the manuscript.

\section{References}

Arthur, J.F., Butterfield, L.H., Roth, M.D., Bui, L.A., Kiertscher, S.M., Lau, R., Dubinett, S., Glaspy, J., McBride, W.H. \& Economou, J.S. (1997) A comparison of gene transfer methods in human dendritic cells. Cancer Gene Ther., $\mathbf{4}$, 17-25.

Banchereau, J., Briere, F., Caux, C., Davoust, J., Lebecque, S., Liu, Y.J., Pulendran, B. \& Palucka, K. (2000) Immunobiology of dendritic cells. Annu. Rev. Immunol., 18, 767-811.

Banchereau, J. \& Palucka, A.K. (2005) Dendritic cells as therapeutic vaccines against cancer. Nat. Rev. Immunol., 5, 296-306.

Breckpot, K., Heirman, C., Neyns, B. \& Thielemans, K. (2004) Exploiting dendritic cells for cancer immunotherapy: genetic modification of dendritic cells. J. Gene Med., 6, 1175-1188.

Brossart, P., Goldrath, A.W., Butz, E.A., Martin, S. \& Bevan, M.J. (1997) Virus-mediated delivery of antigenic epitopes into dendritic cells as a means to induce CTL. J. Immunol., 158, 3270-3276.

Buller, R.E., Shahin, M.S., Horowitz, J.A., Runnebaum, I.B., Mahavni, V., Petrauskas, S., Kreienberg, R., Karlan, B., Slamon, D. \& Pegram, M. (2002) Long term follow-up of patients with recurrent ovarian cancer after Ad p53 gene replacement with SCH 58500. Cancer Gene Ther., 9, 567-572.

Cao, X., Zhang, W., He, L., Xie, Z., Ma, S., Tao, Q., Yu, Y., Hamada, H. \& Wang, J. (1998) Lymphotactin genemodified bone marrow dendritic cells act as more potent adjuvants for peptide delivery to induce specific antitumor immunity. J. Immunol., 161, 6238-6244.

Cerundolo, V., Hermans, I.F. \& Salio, M. (2004) Dendritic cells: a journey from laboratory to clinic. Nat. Immunol., $\mathbf{5}$, 7-10.

Chen, Z., Huang, H., Chang, T., Carlsen, S., Saxena, A., Marr, R., Xing, Z. \& Xiang, J. (2002) Enhanced HER-2/neu-specific antitumor immunity by cotransduction of mouse dendritic cells with two genes encoding HER-2/neu and alpha tumor necrosis factor. Cancer Gene Ther., 9, 778-786.

Davis, I.D., Jefford, M., Parente, P. \& Cebon, J. (2003) Rational approaches to human cancer immunotherapy. $J$. Leukoc. Biol., 73, 3-29.

Dietz, A.B. \& Vuk-Pavlovic, S. (1998) High efficiency adenovirus-mediated gene transfer to human dendritic cells. Blood, 91, 392-398.

Figdor, C.G., de Vries, I.J., Lesterhuis, W.J. \& Melief, C.J. (2004) Dendritic cell immunotherapy: mapping the way. Nat. Med., 10, 475-480.

Frey, B.M., Hackett, N.R., Bergelson, J.M., Finberg, R., Crystal, R.G., Moore, M.A. \& Rafii, S. (1998) High-efficiency gene transfer into ex vivo expanded human hematopoietic progenitors and precursor cells by adenovirus vectors. Blood, 91, 2781-2792.

Gilboa, E. (1999) The makings of a tumor rejection antigen. Immunity, 11, 263-270.

Gilboa, E. \& Vieweg, J. (2004) Cancer immunotherapy with mRNA-transfected dendritic cells. Immunol. Rev., 199, 251-263.

Habib, N., Salama, H., Abd El Latif Abu Median, A., Isac Anis, I., Abd Al Aziz, R.A., Sarraf, C., Mitry, R., Havlik, R., Seth, P., Hartwigsen, J., Bhushan, R., Nicholls, J. \& Jensen, S. (2002) Clinical trial of E1B-deleted adenovirus (d11520) gene therapy for hepatocellular carcinoma. Cancer Gene Ther., 9, 254-259.

Heiser, A., Coleman, D., Dannull, J., Yancey, D., Maurice, M.A., Lallas, C.D., Dahm, P., Niedzwiecki, D., Gilboa, E. \& Vieweg, J. (2002) Autologous dendritic cells transfected with prostate-specific antigen RNA stimulate CTL responses against metastatic prostate tumors. J. Clin. Invest., 109, 409-417.

Homey, B., Muller, A. \& Zlotnik, A. (2002) Chemokines: agents for the immunotherapy of cancer? Nat. Rev. Immunol., 2, 175-184.

Kaplan, J.M., Yu, Q., Piraino, S.T., Pennington, S.E., Shankara, S., Woodworth, L.A. \& Roberts, B.L. (1999) Induction of antitumor immunity with dendritic cells transduced with adenovirus vector-encoding endogenous tumor-associated antigens. J. Immunol., 163, 699-707.

Kikuchi, T. \& Crystal, R.G. (1999) Anti-tumor immunity induced by in vivo adenovirus vector-mediated expression of CD40 ligand in tumor cells. Hum. Gene Ther., 10, 1375-1387.

Kikuchi, T., Moore, M.A. \& Crystal, R.G. (2000a) Dendritic cells modified to express CD40 ligand elicit therapeutic immunity against preexisting murine tumors. Blood, 96, 91-99.

Kikuchi, T., Worgall, S., Singh, R., Moore, M.A. \& Crystal, R.G. (2000b) Dendritic cells genetically modified to express CD40 ligand and pulsed with antigen can initiate antigenspecific humoral immunity independent of CD4+ T cells. Nat. Med., 6, 1154-1159.

Kikuchi, T. \& Crystal, R.G. (2001) Antigen-pulsed dendritic cells expressing macrophage-derived chemokine elicit Th2 responses and promote specific humoral immunity. J. Clin. 
Invest., 108, 917-927.

Kikuchi, T., Hackett, N.R. \& Crystal, R.G. (2001) Cross-strain protection against clinical and laboratory strains of Pseudomonas aeruginosa mediated by dendritic cells genetically modified to express CD40 ligand and pulsed with specific strains of Pseudomonas aeruginosa. Hum. Gene Ther., 12, 1251-1263.

Kikuchi, T., Andarini, S., Xin, H., Gomi, K., Tokue, Y., Saijo, Y., Honjo, T., Watanabe, A. \& Nukiwa, T. (2005) Involvement of fractalkine/CX3CL1 expression by dendritic cells in the enhancement of host immunity against Legionella pneumophila. Infect. Immun., 73, 5350-5357.

Kirk, C.J., Hartigan-O'Connor, D., Nickoloff, B.J., Chamberlain, J.S., Giedlin, M., Aukerman, L. \& Mule, J.J. (2001) T cell-dependent antitumor immunity mediated by secondary lymphoid tissue chemokine: augmentation of dendritic cellbased immunotherapy. Cancer Res., 61, 2062-2070.

Lu, W., Arraes, L.C., Ferreira, W.T. \& Andrieu, J.M. (2004) Therapeutic dendritic-cell vaccine for chronic HIV-1 infection. Nat. Med., 10, 1359-1365.

Lundqvist, A. \& Pisa, P. (2002) Gene-modified dendritic cells for immunotherapy against cancer. Med. Oncol., 19, 197-211.

Matsuyoshi, H., Senju, S., Hirata, S., Yoshitake, Y., Uemura, Y. \& Nishimura, Y. (2004) Enhanced priming of antigenspecific CTLs in vivo by embryonic stem cell-derived dendritic cells expressing chemokine along with antigenic protein: application to antitumor vaccination. J. Immunol., 172, 776-786.

Mellman, I. \& Steinman, R.M. (2001) Dendritic cells: specialized and regulated antigen processing machines. Cell, 106, 255-258.

Mincheff, M., Tchakarov, S., Zoubak, S., Loukinov, D., Botev, C., Altankova, I., Georgiev, G., Petrov, S. \& Meryman, H.T. (2000) Naked DNA and adenoviral immunizations for immunotherapy of prostate cancer: a phase I/II clinical trial. Eur. Urol., 38, 208-217.

Mulders, P., Pang, S., Dannull, J., Kaboo, R., Hinkel, A., Michel, K., Tso, C.L., Roth, M. \& Belldegrun, A. (1998) Highly efficient and consistent gene transfer into dendritic cells utilizing a combination of ultraviolet-irradiated adenovirus and poly(L-lysine) conjugates. Cancer Res., 58, 956-961.

Murphy, A., Westwood, J.A., Teng, M.W., Moeller, M., Darcy, P.K. \& Kershaw, M.H. (2005) Gene modification strategies to induce tumor immunity. Immunity, 22, 403-414.

Nestle, F.O., Banchereau, J. \& Hart, D. (2001) Dendritic cells: On the move from bench to bedside. Nat. Med., 7, 761-765.

Nishioka, Y., Hirao, M., Robbins, P.D., Lotze, M.T. \& Tahara, H. (1999) Induction of systemic and therapeutic antitumor immunity using intratumoral injection of dendritic cells genetically modified to express interleukin 12. Cancer Res., 59, 4035-4041.

Okamura, H., Tsutsi, H., Komatsu, T., Yutsudo, M., Hakura, A., Tanimoto, T., Torigoe, K., Okura, T., Nukada, Y., Hattori, K., Akita, K., Namba, M., Tanabe, F., Konishi, K., Fukuda, S. \& Kurimoto, M. (1995) Cloning of a new cytokine that induces IFN-gamma production by T cells. Nature, $\mathbf{3 7 8}$, 88-91.

O'Sullivan, B. \& Thomas, R. (2003) CD40 and dendritic cell function. Crit. Rev. Immunol., 23, 83-107.

Ribas, A., Butterfield, L.H., Glaspy, J.A. \& Economou, J.S. (2002) Cancer immunotherapy using gene-modified den- dritic cells. Curr. Gene Ther., 2, 57-78.

Rosenberg, S.A., Zhai, Y., Yang, J.C., Schwartzentruber, D.J., Hwu, P., Marincola, F.M., Topalian, S.L., Restifo, N.P., Seipp, C.A., Einhorn, J.H., Roberts, B. \& White, D.E. (1998) Immunizing patients with metastatic melanoma using recombinant adenoviruses encoding MART-1 or gp100 melanoma antigens. J. Natl. Cancer Inst., 90, 1894-1900.

Rouse, R.J., Nair, S.K., Lydy, S.L., Bowen, J.C. \& Rouse, B.T. (1994) Induction in vitro of primary cytotoxic T-lymphocyte responses with DNA encoding herpes simplex virus proteins. J. Virol., 68, 5685-5689.

Sharma, S., Batra, R.K., Yang, S.C., Hillinger, S., Zhu, L., Atianzar, K., Strieter, R.M., Riedl, K., Huang, M. \& Dubinett, S.M. (2003) Interleukin-7 gene-modified dendritic cells reduce pulmonary tumor burden in spontaneous murine bronchoalveolar cell carcinoma. Hum. Gene Ther., 14, 1511-1524.

Steinman, R.M. \& Pope, M. (2002) Exploiting dendritic cells to improve vaccine efficacy. J. Clin. Invest., 109, 1519-1526.

Su, Z., Dannull, J., Heiser, A., Yancey, D., Pruitt, S., Madden, J., Coleman, D., Niedzwiecki, D., Gilboa, E. \& Vieweg, J. (2003) Immunological and clinical responses in metastatic renal cancer patients vaccinated with tumor RNA-transfected dendritic cells. Cancer Res., 63, 2127-2133.

Tatsumi, T., Gambotto, A., Robbins, P.D. \& Storkus, W.J. (2002) Interleukin 18 gene transfer expands the repertoire of antitumor Th1-type immunity elicited by dendritic cell-based vaccines in association with enhanced therapeutic efficacy. Cancer Res., 62, 5853-5858.

Tatsumi, T., Huang, J., Gooding, W.E., Gambotto, A., Robbins, P.D., Vujanovic, N.L., Alber, S.M., Watkins, S.C., Okada, H. \& Storkus, W.J. (2003) Intratumoral delivery of dendritic cells engineered to secrete both interleukin (IL)-12 and IL-18 effectively treats local and distant disease in association with broadly reactive Tc1-type immunity. Cancer Res., 63, 6378-6386.

Trinchieri, G. (1993) Interleukin-12 and its role in the generation of TH1 cells. Immunol. Today, 14, 335-338.

Van Tendeloo, V.F., Snoeck, H.W., Lardon, F., Vanham, G.L., Nijs, G., Lenjou, M., Hendriks, L., Van Broeckhoven, C., Moulijn, A., Rodrigus, I., Verdonk, P., Van Bockstaele, D.R. \& Berneman, Z.N. (1998) Nonviral transfection of distinct types of human dendritic cells: high-efficiency gene transfer by electroporation into hematopoietic progenitor- but not monocyte-derived dendritic cells. Gene Ther., 5, 700-707.

Wang, R.F., Wang, X., Atwood, A.C., Topalian, S.L. \& Rosenberg, S.A. (1999) Cloning genes encoding MHC class II-restricted antigens: mutated CDC27 as a tumor antigen. Science, 284, 1351-1354.

Wiethe, C., Dittmar, K., Doan, T., Lindenmaier, W. \& Tindle, R. (2003) Enhanced effector and memory CTL responses generated by incorporation of receptor activator of NFkappa B (RANK)/RANK ligand costimulatory molecules into dendritic cell immunogens expressing a human tumorspecific antigen. J. Immunol., 171, 4121-4130.

Yang, S.C., Hillinger, S., Riedl, K., Zhang, L., Zhu, L., Huang, M., Atianzar, K., Kuo, B.Y., Gardner, B., Batra, R.K., Strieter, R.M., Dubinett, S.M. \& Sharma, S. (2004) Intratumoral administration of dendritic cells overexpressing CCL21 generates systemic antitumor responses and confers tumor immunity. Clin. Cancer Res., 10, 2891-2901. 